\title{
II. Observations on the preceding memoir
}

\author{
Sir David Brewster K.H. LL.D. F.R.S. V.P.R.S. Ed.
}

To cite this article: Sir David Brewster K.H. LL.D. F.R.S. V.P.R.S. Ed. (1832) II.

Observations on the preceding memoir , Philosophical Magazine Series 3, 1:1, 6-9, DOI:

10.1080/14786443208647809

To link to this article: http://dx.doi.org/10.1080/14786443208647809

$$
\text { 曲 Published online: } 01 \text { Jun } 2009 .
$$

Submit your article to this journal $\complement$

\section{山 Article views: 3}


6 Sir D. Brewster's Observations on M. Rudberrg's Memoir.

The indices given by Malus are $1 \cdot 6543$ and $1 \cdot 4833$. Calling, as before, $n^{\prime}$ the index of the ordinary ray, and $n^{\prime \prime}$ that of the extraordinary ray, we have the following values of the ratio $\frac{n^{\prime}}{n^{\prime \prime}}$.

$$
\begin{array}{ll}
\text { H } & 1 \cdot 12385 \\
\text { G } & 1 \cdot 12154 \\
\text { F } & 1 \cdot 11891 \\
\text { E } & 1 \cdot 11750 \\
\text { D } & 1 \cdot 11582 \\
\text { C } & 1 \cdot 11440 \\
\text { B } & 1 \cdot 11400
\end{array}
$$

From which we see incontestably the increase of the double refraction with the individual refrangibility of the colour.

[To be continued.]

II. Observations on the preceding Memoir. By Sir David Brewster, K.H. LL.D. F.R.S. V.P.R.S. Ed.

I $T$ is impossible to estimate too highly the value of the ob1 servations contained in the preceding memoir. To the mineralogist, as well as to the optical philosopher, such observations are fixed data of the highest utility.

The only general conclusion, however, which M. Rudberg has drawn from his experiments in the first part of his memoir, is, that the double refraction increases with the refrangibility of the coloured ray; or, to express the same fact in other words, that the dispersion produced by the extraordinary refraction is greater in proportion to the mean refraction than that produced by the ordinary refraction, - or that doubly refracting crystals have two different dispersive powers.

This discovery was made by myself so long ago as 1812 , and an account of it published in my Treatise on New Phi losophical Instruments, Edinb. 1813, p. 312-315: in the Philosophical Transactions, 1813, p. 107; and in the article Optics, in the Edinburgh Encyclopædia, vol. xv. p. 544. The following is the account of it, which I have published in the first of these works.

"The most singular result, however, which is contained in the following table (Table of Dispersive Powers) relates to the dispersive powers of doubly refracting substances. The first experiment which I made upon crystals, was to determine the dispersive power of Iceland spar; and from a cause merely accidental, I corrected the colour of the least refraction. The result thus obtained was 0.026 , considerably below water, 
which stands at 0.035 of the scale; and upon comparing it with the place assigned to Iceland crystal by Dr. Wollaston, I was surprised to find that he placed its dispersive power very considerably above water, and even above diamond. This unexpected difference between the two measures induced me to repeat the experiments, not only with other prisms of the Iceland spar, but also with other standard prisms of flint and crown glass. These new results served only to confirm the accuracy of the first experiment, and to strengthen my suspicion that Dr. Wollaston had committed a mistake. As this reasoning, however, was founded on the assumption which both Dr. Wollaston and I had made,-that the spar had only one dispersive power, -I resolved to measure the dispersive power of the extraordinary refraction. This new value having turned out to be greater than that of water, I immediately saw that Dr. Wollaston had measured the colour of the greatest refraction, while I had measured the colour of the least; and that this remarkable mineral, which had so long perplexed philosophers by its double refraction, possessed the no less extraordinary and inexplicable property of two dispersive powers. In subjecting to examination other crystals that afforded double images, - such as carbonate of strontites, carbonate of lead, and chromate of lead,-I found that every separate refraction possessed a separate dispersive power. This general law, though not repugnant to any optical phænomena, is still of such a nature, that it could not have been inferred à prior $i$ from any relation which is known to subsist between the refractive and dispersive powers. No person, indeed, has even conjectured that a double dispersive should accompany a double refractive power: and if we were to reason in this case from an analogy founded on experiment, - an analogy, too, which is by no means remote, we should certainly conclude, contrary to the fact, that the greatest refractive power would be accompanied with the least power of dispersion. In all the minerals in which a metal is the principal ingredient, those which have the greatest refractive density have also the greatest faculty of producing colour; while in all the precious stones a high refractive power is attended with a low power of dispersion. This remarkable property of a double dispersion, therefore, is contrary to the general results indicated by experiments; and though it appears to exclude some of the theories by which a double refraction has been explained, it certainly adds another to those numerous difficulties with which philosophy has yet to struggle, before she can reduce to a satisfactory 


\section{Sir D. Brewster's Observations on M. Rudberg's Memoir.}

generalization the anomalous and capricious phænomena which light exhibits in its passage through transparent bodies."

In comparing the results abtained by M. Rudberg with calcareous spar with those obtained by Malus, we have been struck with a discrepancy so great that we cannot find any explanation of it.

Malus found the two indices for quartz to be 1.55817 and 1.54843. Now if we compare these numbers with those of M. Rudberg, we shall. find that they both correspond to a ray towards the extremity of the green space between the lines $\mathrm{E}$ and F. Thus

$$
\begin{array}{lcclcc}
\multicolumn{4}{c}{\text { Extraor. Ray. Diff. }} & \text { Ordin. Ray. Diff. } \\
\text { Rudberg... } & \text { F } & 1.55894 & & 1.54965 & \\
\text { Malus ...... } & & 1.55817 & 77 & 1.54843 & 122 \\
& \text { E } & 1.55631 & 186 & 1.54711 & 132
\end{array}
$$

Hence Malus's extraordinary index corresponds to a ray whose distance from $\mathrm{F}$ is 77 ; while his ordinary index corresponds to a ray whose distance from $\mathrm{F}$ is 122 . This discrepancy is not at all to be wondered at, and shows us how uncertain are all measures of refractive powers unless they are referred to the fixed lines in the spectrum.

The case is widely different, however, with calcareous spar, as the following table shows.

\begin{tabular}{lrllrl} 
& \multicolumn{2}{c}{ Ord. Index. } & Diff. & & Extr. Index. Diff. \\
Rudberg... C & $1 \cdot 65452$ & & B $1 \cdot 48391$ & 1 \\
Malus..... & $1 \cdot 65429$ & 23 & & $1 \cdot 48330$ & 61 \\
Rudberg... B & $1 \cdot 65.308$ & 121 & &
\end{tabular}

Here the results of Malus and Rudberg are widely divergent. Malus used the middle green ray of the spectrum (Théorie de la Double Refraction, Deux. Parte, $\S 42$ ), or that which is half way between $E$ and $F$, and yet his mean ordinary index corresponds with one of the red rays in Rudberg's observations! Assuming the same ray in both observations, the mean ordinary index will be as follows:

$$
\begin{array}{lll}
\multicolumn{4}{c}{\text { Mean Ord. Index. Diff. }} \\
\text { Rudberg...... } & 1 \cdot 66585 & 1156 \\
\text { Malus ......... } & 1 \cdot 65429 & 156
\end{array}
$$

In the case of the extraordinary ray the discrepancy is still more surprising. Here the mean index of Malus corresponds to a ray distant 61 from $\mathrm{B}$, and existing beyond the end of the visible spectrum formed by light of ordinary intensity. Assuming 
the same ray in both observations as the mean one, the mean extraordinary index will be as follows:

$$
\begin{aligned}
& \multicolumn{4}{c}{\text { Mean Extr. Index. Diff. }} \\
& \text { Rudberg................ } 1 \cdot 48971 \\
& \text { Malus................ } 1 \cdot 48330
\end{aligned}
$$

Dr. Wollaston gives the two indices according to his measurements, as 1.657 and 1.488 , which are nearer those of $M$. Rudberg; but as Dr. Young has assured us that the measures taken by Dr. Wollaston are appropriate to the extreme red rays, they throw no light upon the cause of the discrepancy under our consideration. The discrepancies, indeed, become more alarming, and will stand thus, by calling $B$ the extreme red ray, and calculating its index from Malus's index for the middle green.

\begin{tabular}{lcc} 
& \multicolumn{2}{c}{ Red Ray B. } \\
Ordinary. & Extraordinary. \\
Wollaston ... & $1 \cdot 65700$ & $1 \cdot 48800$ \\
Rudberg...... & 1.65308 & 1.48391 \\
Malus ......... & 1.64152 & 1.47750
\end{tabular}

Hence it appears that Wollaston's measures are greater than those of Rudberg, and still more remote from those of Malus.

As it is impossible to suppose for a moment that either Malus or Rudberg could have committed errors of observation capable of reconciling these results, we are forced to conclude, that the experiments of each were made with crystals of calcareous spar which had different degrees of refractive power, - a conclusion which deprives us of the hope of obtaining invariable physical data for different minerals. Such a result, indeed, might have been expected from the variety of specific gravities which different specimens of calcareous spar exhibit; and all that science can hope to accomplish on this subject, is to define the general limits within which these variations are confined.

III. Observations respecting the Invention of the Telescope. By J. E. Dhinkwatek, Esq.*

A VERY interesting article on the invention of telescopes $A$ is printed in the second and third Numbers of the Journal of the Royal Institution, in which it is clearly proved that John Lippershey, a spectacle-maker of Middleburg, possessed the invention on the 2nd of October, 1608: that Jacob Adri-

* Communicated by the Author:-In the first series of Phil. Mag. vol.xviij. p. 245 , and vol. xix. p. 66 , will be found two letters, with extracts from old English books, from which the writer infers that the telescope was known in England long before the period of its reputed invention.-EDIT.

Third Series. Vol. 1. No. 1. July 1832. 